\title{
Piel de lava: grupalidad y matrices discursivas para las praxis de una escena teatral argentina
}

- Carla Pessolano

IIT-UNA/CONICET/UBA, Argentina

carlapessolano@hotmail.com

Fecha de recepción: 24/02/2021. Fecha de aceptación: 20/03/2021.

En este trabajo se intentará hacer un primer relevamiento metaforológico (Blumenberg, 2003) de los discursos de espesor del grupo teatral Piel de Lava para dar cuenta del modo en que su formación en actuación y dramaturgia, al comienzo de sus carreras, implantó una forma de creación que influye hasta hoy en sus procedimientos y en sus reflexiones acerca de los mismos. Al hacerlo, se estipula que los decires a partir de los cuales las y los artistas refieren a sus prácticas impactan de manera explícita en el sentido que le asignan al mundo y a su creación. De esta manera, intentaremos dar cuenta de cómo se organizan las matrices discursivas con las que este grupo de creadoras refiere a sus praxis, conformando no solo un decir acerca de las mismas sino también un pensamiento específico sobre la práctica escénica toda.

PALABRAS CLAVE: PRÁCTICAS ESCÉNICAS, PRAXIS ACTORAL, DISCURSOS DE ESPESOR, METAFOROLOGÍA, DRAMATURGIA ARGENTINA.

\section{Piel de lava: Groupality and Theatrical Matrices for the Praxis of an Argentinean Theatrical Scene}

This paper aims to create a first survey of the thick discourses in Piel de Lava's troupe from Blumenberg's Paradigms for a Metaphorology point of view. The group's training in acting and dramaturgy established a way of creation that is still influencing their procedures and their thinking. By doing it, we stipulate that the speeches from where artists refer to their own practices explicitly impact in the sense given to the world and their creation. Is in this way that we will try to set how the group's discursive matrices are organized when referring to their own praxis, conceiving that this not only shapes a discourse about these practices but also specific thoughts about the scenic practices as a whole.

KEYWORDS: SCENIC PRACTICES, ACTING PRAXIS, THICK DISCOURSES, METAPHOROLOGY, ARGENTINEAN DRAMATURGY. 


\section{Introducción}

Piel de Lava es una banda de mujeres que hace teatro desde hace años: son un grupo de creadoras, una compañía teatral y una pandilla de amigas. Sus obras se fueron sucediendo desde 2003 con un tipo de abordaje escénico que fue variando, pero siempre sosteniendo la prueba de lo grupal como centro. El presente artículo buscará indagar en los decires de este grupo -reconociblemente- singular dentro de la escena teatral porteña. Al hacerlo, se intentará dar cuenta de los modos en que se organizan las matrices discursivas con las que refieren a sus praxis, conformando no solo un decir acerca de las mismas sino también un pensamiento específico sobre la práctica escénica toda. En su caso, la concepción de lo grupal como "posición política", la búsqueda de lo que llaman "cimiento" de la creación que se apoya en notas, percepciones grupales e imágenes y la elaboración de una concepción de la profesionalización conjunta son algunos de los principales recursos que dan textura a la trama de creación en común que se apoya en lo colectivo desde el comienzo de su colaboración.

Como he apuntado en trabajos anteriores, a partir de rastrear los modos en que los artistas refieren a sus prácticas, me permito pensar en una serie de conceptos que se forjan "como herramientas con el roce de lo real", al decir de Marie Bardet (2012: 24). Esto sería, enunciaciones que, sin voluntad totalizante, rondan las praxis distinguiendo diversas concepciones de mundo. Podría pensarse que es en estas terminologías puntuales donde reside gran parte de la memoria lingüística que irradia la escena teatral de un territorio, en este caso el teatro porteño. Dentro de la configuración de lo colectivo, esto termina de reafirmarse en lo que Alberto Ure llama "el lenguaje sordo de los grupos" (2003: 71) que no solo abarca los decires específicos internos al encuentro del tejido grupal sino también al imaginario en común que tiende las redes para que ese tejido exista.

Cabe destacar que el desarrollo teórico aquí presentado forma parte de una investigación de amplio alcance centrada en el estudio de determinadas metáforas que circulan en el campo teatral argentino y que tienen la potencia de configurarse como uno de los principales vectores para articular los saberes que lo constituyen. Específicamente, en el marco del proyecto Filocyt en el cual se inscribe este trabajo, me he ocupado de presentar una tradición dramatúrgica ligada a las poéticas del cuerpo. Así es que, a partir de diversos decires de un grupo de creadoras y creadores del campo teatral nacional, he indagado sobre la elaboración de pensamiento acerca de las prácticas escénicas, dando cuenta de un tipo de teatro centrado en los cuerpos de actuación y en el modo en que esa percepción se ha implantado en ciertos abordajes escriturales. El caso de Piel de Lava, sin lugar a dudas, se inscribe dentro de esa tradición del campo teatral nacional y forma parte de un corpus integrado por artistas reconocibles como los principales exponentes en lo que refiere a la valoración del cuerpo de actuación como resistente.

En mi tesis doctoral y también en artículos anteriores he desarrollado la noción de resistencia para leer la praxis teatral argentina contemporánea. Basándome en el constructo teórico que Osvaldo Pellettieri (1998) elaboró a fines de los noventa, la resistencia se configura como una concepción de la práctica teatral en que el cuerpo de actuación se concibe como un territorio que se enfrenta al orden homogeneizante y hegemónico en las prácticas de la escena. Esto se da, especialmente, a partir de un trabajo escénico que pone por delante la búsqueda de un cuerpo poético que produce sentidos múltiples, como forma de micropolítica desde la praxis de actuación y como producción de pensamiento en la práctica (Pessolano, 2019). La particularidad de esta observación se apoya en que la resistencia reside no únicamente en una mirada específica acerca del fenómeno actoral, sino también en la producción de material 
reflexivo que da cuenta de esa mirada. De este modo, por el tipo de registro al que acuden en determinados momentos de sus creaciones, como así también por su concepción de escena mutante pero centrada en los cuerpos de actuación (especialmente desde su última producción, Petróleo), el grupo Piel de Lava funciona como referencia de un abordaje escénico legible a partir de las dimensiones específicas del teatro de resistencia actual.

Agregado a esto, y en función la extracción de determinados sintagmas propios de sus desarrollos metarreflexivos (recuperados desde diversas fuentes heterogéneas pero, especialmente, tomando dos artículos escritos por las integrantes del grupo), me apoyo en la perspectiva conceptual que desarrolla Hans Blumenberg para pensar tanto conceptos como sistemas teóricos, que es lo que podemos captar al compilar la serie de recursos poéticos y recursos técnicos que utilizan estas creadoras para sistematizar y describir sus praxis de creación.

Lo relevante de esta teoría para pensar en las praxis de la escena teatral argentina contemporánea es la idea desarrollada por Blumenberg de que "el lenguaje se encuentra detrás de nuestra visión del mundo" (Blumenberg, 2003: 105). Esto jerarquizaría la posibilidad de una "textualidad cifrada" (2003) o una "escritura secreta" (2003) que da cuenta, más que de una verdad desnuda, de una concepción singular que propone microsistemas teóricos que se implantan como redes del decir y del hacer dentro de diversas praxis específicas. Así es, por ejemplo, que en el sistema teórico de este grupo de mujeres la idea de "dispositivos de actuación" aparece bajo la modalidad de "fe en la prueba" (Paredes, 2018), una especie de creencia que excede toda sistematización posible porque lo que predomina es la apuesta a configurar una acción capaz de propiciar indagaciones de tipos diversos que luego redundarán en una poética específica.

Con este fin, y a partir de una primera lectura metaforológica, tal como propone Blumenberg, lo ideal sería poder desplegar un análisis de esas formas específicas del decir grupal que -no sin cierta opacidad- se instalan como recurso que da cuenta del modo en que ese colectivo de actrices conoce el teatro y el mundo en que inserta sus prácticas. Como se mencionó anteriormente, estas cuestiones han sido analizadas previamente en el marco de los decires de diversos creadores y creadoras de resistencia (Alberto Ure, Eduardo Pavlovsky, Ricardo Bartís, Alejandro Catalán, Bernardo Cappa, Analía Couceyro y Sergio Boris), llegando incluso a generar ligazones y captando herencias entre decires comunes que los conformarían como red dentro del campo teatral nacional. Sin embargo, la particularidad de este caso testigo es que se piensan los decires específicos que se fundan en la fricción de la interacción grupal. Para estudiar estas cuestiones, me interesaré especialmente por la configuración procesual de la dramaturgia que -según los dichos de las integrantes de Piel de Lava-da pie a su abordaje específico de la creación colectiva.

\section{Un pensamiento desde lo contingente}

En el año 2003, Piel de Lava se constituye como grupo a partir del encuentro de Pilar Gamboa, Elisa Carricajo, Laura Paredes y Valeria Correa. Desde ese momento y hasta la actualidad, han trabajado ininterrumpidamente como colectivo de creación. Colores verdaderos (2003), Neblina (2006), Tren (2010), Museo (2014) y Petróleo (2018) son los rastros devenidos obra de esos procesos de creación conjunta. El grupo trabaja también, en algunos casos, con la directora y dramaturga Laura Fernández que codirigió tres de estas obras. Respecto de su método de trabajo, los lineamientos sobre los que desarrollan sus búsquedas escénicas rondan la dramaturgia en grupo, la dirección y la actuación. 
En su concepción de la grupalidad como práctica política, estas creadoras riman sus dinámicas de trabajo horizontales con el movimiento feminista. Así lo dirá en entrevista Valeria Correa: "Creo que la horizontalidad es feminista. Es lo que propone el feminismo. No digo que sea algo exclusivo de la mujer, pero lo tiene entrenado. Porque para sobrevivir lo tenés que desplegar" (Yaccar, 2019). Además de esta perspectiva específica -que se acentúa en sus dichos de los últimos años-, algunas de las temáticas recurrentes respecto de su pensamiento grupal acerca del teatro suelen ser: la profesionalización; la búsqueda de un lenguaje conjunto para la escritura en colectivo; cuestiones en torno a dispositivos de actuación y formatos de prueba para dar con una actuación singular; la detección de un "decir del material"; la toma de los vínculos humanos en tanto material dramático específicamente; ideas en torno al "afuera" y al "adentro" de la escena como categorías "difusas, permeables, flexibles" (Piel de Lava, 2015); y, finalmente, la idea de lo que llaman "modo ensayo" que sería un espacio de búsqueda peculiar para la creación artística que transitan como una especie de situación "impuesta":

Nos juntamos a probar ideas, textos y materiales que nos motorizaron a empezar una nueva obra. Siempre llamamos a esa instancia "ensayar" aunque a veces lo que se ensaya no existe todavía. Es como una forma de estar en el tiempo, juntándonos, compartiendo la cotidianeidad, probando casi siempre durante largas temporadas cosas que no conducirán a ningún sitio" (Piel de Lava, 2015: 127).

En este caso, la definición acerca de la propia metodología se vuelve determinante de la poética que construyen, desde la articulación de esas ideas de grupalidad y ensayo permanente. Dentro de esa articulación, aparece también la posibilidad de autonomía que les da la dramaturgia colectiva cuando de la colaboración emana una presencia de otredad, lo que ellas llaman "un integrante fantasma que mueve los hilos desde su perverso escritorio" (Piel de Lava, 2015: 129).

Cabe destacar que gran parte de estos desarrollos conceptuales se afincan, según sus propias descripciones, en un momento clave de su encuentro, en talleres de actuación y dramaturgia. Aluden a que la formación en esos talleres hizo que la grupalidad se instale como un modo de producción posible y sistemático. Así lo apuntarán en un material reflexivo que da cuenta de lo grupal como posibilidad de "desmesura" en lo escritural:

La creación grupal tiene una energía desmesurada y caótica y eso muchas veces asusta. Enfrentarnos a ese caos es lo que muchas veces nos hace pensar que debemos abandonar esa dinámica en lugar de encontrar formas y sistematizaciones para hacerla funcionar. No es sencillo encontrar esos modelos de organización y menos inventarlos, y es por eso que creo que hay que volver a esas viejas formas de organización de los talleres y pensar cómo lo hacíamos. ¿Cómo lo hacíamos? Quizás la respuesta es más bien sencilla: simplemente lo hacíamos. Nos juntábamos, discutíamos hasta ponernos de acuerdo, ensayábamos, mostrábamos y seguíamos trabajando. Y algo se empezaba a iluminar en esa prueba que nos hacía empezar a tener conciencia de un norte, de una búsqueda, de un mundo en particular. (Paredes, 2018)

En 2018, el grupo fue convocado por Vivi Tellas al programa "Artistas en residencia" para hacer una retrospectiva sobre sus trabajos escénicos previos, para desarrollar la creación de una nueva obra (que sería Petróleo) y dar un seminario sobre creación grupal en el Teatro Sarmiento del Complejo Teatral de Buenos Aires. Frente a esta posibilidad de repensar retrospectivamente el propio trabajo y buscar el modo de transmitirlo, en el marco de ese workshop, el grupo detecta una pregunta que nuclea gran parte de la problemática que conduce su creación 
desde hace tiempo, incluso sin saberla evidente. La pregunta, que formula Laura Paredes en un artículo para la revista de dramaturgia La llave universal, reza:

¿Por qué en los talleres de producción nos formamos aprendiendo a hacer todo -y cuando me refiero a "todo", me refiero a pensar la escena desde adentro y afuera, escribir mis propios textos, tomar nota constante de las improvisaciones propias y de las de mis compañeros, pensar en mi vestuario y en el de mis compañeros, tomar las decisiones de una posible puesta lumínica, etc.- y cuando ya no formamos parte del taller nos dedicamos a tomar las decisiones de una forma diametralmente opuesta a como la aprendimos?

Por lo tanto, pareciera ser que esta diferencia entre la creación durante la formación y la creación en la instancia profesional es justamente la posibilidad de sostener un "pensar con otros" (Paredes, 2018). Estas cuestiones se fueron implantando en su trabajo y explicitando gracias a ese seminario de 2018 en que el grupo de creadoras sistematizó su metodología para compartirla. Esto confirmaría que, tal como lo argumenta el proyecto Filocyt en el cual se inscribe esta investigación, la formación en dramaturgia dentro del campo teatral nacional cimentó la construcción de un territorio de saberes específico en la historia del teatro argentino que se vuelve manifiesta en diversas lógicas procesuales grupales, siendo el caso de estas creadoras un ejemplo que resulta ineludible. Así será que, en otros trabajos, referirán a que esa diferencia se da principalmente por un tránsito formativo específico que rondaron especialmente dos de las integrantes (Laura Paredes y Valeria Correa): diversos talleres privados de dramaturgia y la carrera de dramaturgia en la Escuela Metropolitana de Arte Dramático.

Si en estos espacios se instala una escritura que se apoya en la multiplicidad de voces desde el pasaje por diversos puntos (una instancia de escritura individual, instancias de socialización de esos escritos, una devolución del docente y observaciones de parte del grupo sobre el material), se comprende la puesta en valor de la "prueba" que se instala en la búsqueda de un universo escritural para la escena. Estas líneas incluso definen un espacio de producción singular que pone en tensión una concepción de la dramaturgia como trabajo en absoluta soledad y una jerarquización de la pluralidad de voces en el diálogo con los trabajos en curso durante los procesos escriturales. Por otra parte, esta lógica formativa pone en valor las instancias del trabajo desde la socialización de un material escritural que se va configurando "por capas" bajo la mirada de docentes y pares.

Estos recursos singulares del trabajo en talleres de formación en dramaturgia (así como otros recorridos compartidos en espacios de formación actoral) han cimentado el modo de creación de las Piel de Lava, cuando jerarquizan los saberes puestos en circulación en estos espacios de formación dramatúrgica siendo en el caso de ellas el modo en que conciben la posibilidad de una profesionalización. Así afirma Pilar Gamboa en la entrevista: "El trabajo es genuinamente el resultado del pensamiento de cinco cabezas. Habla por sí solo. En los talleres en los que nos formamos, la dramaturgia grupal era la manera de pensar el teatro. Siempre nos preguntamos en qué momento, cuando uno se profesionaliza, se pierde esa grupalidad" (Yaccar, 2019). En muchos casos, respecto de los procesos de creación escritural ellas referirán puntualmente a la necesidad de una especie de desdoblamiento entre "las actrices" y "las dramaturgas" que son los roles que ocupan simultáneamente durante la creación escénica. En contraposición a ese tipo de abordaje específico -durante la escritura de una obra en soledad-, Laura Paredes referirá: "Me cuesta mucho escribir sola, no tengo esa gimnasia. Lo hice en el terreno del taller, esa exigencia me hace escribir" (Yaccar, 2017). 


\section{El simulacro de un simulacro}

Cuando este grupo de creadoras comenzó a estudiar y compartió espacios formativos, a mediados de los ‘ 90 , el contexto escénico en Buenos Aires propiciaba espacios y estudios privados en que imponía la llamada dramaturgia del actor. Esto se inscribe dentro de las poéticas de creadores de resistencia que aparece como respuesta a un momento previo de preeminencia del texto como centro de la escena. Es decir, que frente a un teatro en que lo logocéntrico es fundante (imponiéndose incluso como forma de hegemonía), el trabajo sobre los cuerpos de actuación como principales productores de sentido se reafirmaba y buscaba su cauce. Ricardo Bartís, uno de los exponentes principales en esta línea, dirá al respecto:

Nuestra experiencia tenía que ver más con lo escénico desde la actuación y la reflexión de los problemas desde el lugar de la actuación, que desde la dirección o la escritura. También había una necesidad, en ese momento, de reivindicar el espacio de la actuación desde un lugar nuevo, donde el actor pudiera pensar, tener un discurso propio, no someterse a las ideas de la dirección (Bartís, 2003: 116).

Dentro de este abordaje escénico, entonces, el cuerpo de actuación se propone como material base para producir un lenguaje de creación específico, los vínculos se instalan como material dramático y el ensayo se configura como el espacio en que puede delinearse una poética singular. Sumado a estas particularidades, esto se instala en un momento del teatro nacional en que se fomentaba que los estudiantes generaran sus propios materiales de modo horizontal, dando lugar a escrituras colectivas que daban cuenta de la búsqueda de un lenguaje conjunto. Ese contexto de encuentro en que se produjo el germen de esta grupalidad particular no es menor dentro de la genealogía de este colectivo. Incluso hoy en día estas creadoras referirán dentro de sus matrices discursivas a los "dispositivos de actuación" que se sostienen desde la "fe en la prueba" (Paredes, 2018) y al "afuera" y al "adentro" de la escena como una lógica de creación que se entrena al "asumir el conocimiento que el actor tiene de la escena" (Paredes, 2018), dialogando con el exterior "sin jerarquías previas" (Paredes, 2018).

Por lo tanto, si se piensa la escena desde un afuera-adentro permanente, el ensayo deja de entenderse como una suma de personas y se conforma como "una cosa más que humana" (Ure, 2003), tal como lo precisaba Alberto Ure. Aquel evento efímero, único e irrepetible que se da en el encuentro entre esas personas. Esa "maleza" (Piel de Lava, 2015), esa "desmesura" (Paredes, 2018), tal como concibe este grupo de creadoras a la creación grupal, da cuenta de una "subjetividad compartida" (Piel de Lava, 2015) o, como detallarán, una mirada del mundo en común que funciona como "recorridos de mapa de un mismo GPS" (Piel de Lava, 2015: 126). Dirán al respecto: "con una misma voz que nos orienta y nos confunde pero siempre la tranquilidad de estar hablando un mismo idioma" (Piel de Lava, 2015: 126). De hecho, es curioso cómo este grupo de creadoras le da entidad especial a esa dinámica de trabajo cuando define aquella idea propia de "modo ensayo" (Piel de Lava, 2015), el cual les permite, además, una especie de proyección temporal hacia atrás y hacia adelante:

Ni aun cuando se piensa solo se piensa realmente solo. Los otros están ahí, en esa soledad que evoca la grupalidad hacia el pasado (porque partimos desde lo que ya se trabajó juntas) y hacia el futuro (porque será hecho para probarlo en la arena donde el grupo se desenvuelve). (Piel de Lava, 2015: 126)

En ese espacio de búsqueda, que mucho tiene que ver con una concepción de escena apoyada en los cuerpos de actuación, se impone el ensayo como un "laboratorio" 
(Piel de Lava, 2015) de donde surge un "monstruo-obra" (Piel de Lava, 2015), especie de "Frankestein" (Piel de Lava, 2015) -dirán- en mutación permanente. De hecho, esta lógica de creación le da a la grupalidad una entidad autónoma y única: aquello "que el grupo sabe" es la "piedra preciosa" que se impone en el entretejido entre escritura y cuerpos en escena más allá de las individualidades: "Y ahí está la piedra preciosa, esa imagen que no aparecía, ese texto que no cerraba del todo, eso que puede iluminar la actuación" (Paredes, 2018).

Esta especie de "democracia suspendida" y de "desmenuzamiento de la mayoría" funcionaría, dentro de esta lógica, para ir en busca de aquello que tiene para decir el material: "la expresión «gana la mayoría» iría muchas veces en contra del espíritu del trabajo" (Paredes, 2018) porque se entiende que no se trata de buscar un consenso sino de ir en pos de lo que "la obra pide". Así es que el saber de la grupalidad, aquella "piedra preciosa" excede por mucho la discusión sobre la idea:

Hay algo que el grupo sabe, más allá de nosotras y sé que suena místico o ramplón pero es milagroso. Siempre está un poco adelantado. Y muchas veces nos rompemos la cabeza tratando de descubrir algo de la obra y un día cualquiera, mientras la vida y los ensayos avanzan, aparece la voz del grupo, se hace palabra en boca de alguna, se manifiesta y dice: “¡Ey! ¡Es por acá! ¡Miren!” (Paredes, 2018).

Así es que -remitiendo a Museo y la obra que era el centro de la trama- dirán que cada una de sus obras opera como un "cuerpo solo" (Piel de Lava, 2015), un material que cuenta en sí mismo con una "inteligencia aparte" (Piel de Lava, 2015: 128) una "inteligencia sensible" que por momentos pareciera dialogar con las creadoras y en otros simplemente hablara en "otro idioma" (Piel de Lava, 2015: 128).

Por lo tanto, si "cada idea no se discute sino que se prueba" (Piel de Lava, 2015) la operatoria de la grupalidad muestra un apoyo último en la escena, dejando en evidencia, la acción de un pensamiento compartido que es el de la lógica de los cuerpos de actuación.

Se permitirán, desde estas concepciones de teatro, hablar de la "fricción" (Piel de Lava, 2015) y de la "explosión" (Piel de Lava, 2015) que se produce "cuando varias personas piensan a la vez" (Piel de Lava, 2015). Asimismo, se iluminará aquel procedimiento por el cual los aglutinantes indiscutidos de la creación colectiva son aquellos que se definen desde las primeras anotaciones, tal como sucedía en esos espacios formativos compartidos y en esa escritura por capas de los talleres de dramaturgia. Esas "notas" de proceso son, según estas creadoras, "los cimientos para poder organizar la escritura y partir -en paralelo a los dispositivos de actuación- desde una lógica compartida, percibida por todos los miembros del grupo y que pudiera volverse síntesis en algunas pocas palabras" (Paredes, 2018). En esa síntesis concreta radicará esa especificidad que terminará de matizar la grupalidad.

Ese "monstruo de cuatro cabezas" (Paredes, 2018), como refieren ellas mismas a su grupo, da cuenta de una horizontalidad intrínseca que toma al movimiento feminista como modelo que podría servir para generar una transformación profunda de las praxis de creación. Sus recursos técnicos, así como sus recursos poéticos, permiten pensar en lo que describen como una forma de creación de resistencia que se apoya en los vínculos elegidos por encima de una institución que sostenga esos lazos. Así, más allá de las tensiones respecto de la profesionalización que estas actrices buscan poner en perspectiva permanentemente en su trabajo, las tramas de grupalidad operan como un modo de mantener los recursos de la formación en talleres que aún hoy se encuentra vigente en la operatoria nuclear de su concepción de lo que significa ser un grupo. 


\section{Conclusiones}

"¿Por qué se vuelve tan difícil con los años pensar con otros?" (Paredes, 2018), se pregunta Laura Paredes respecto de las modalidades de creación dentro de la escena teatral de Buenos Aires de la cual forma parte junto con Piel de Lava. Ligado a esto, las dificultades de las praxis grupales y su sostén en el tiempo, la segmentariedad de los espacios profesionales de la escena, la formación en talleres como una etapa a superar para aspirar a la contención de una institucionalidad más rígida y cuestiones en torno a la consagración personal en el campo de las praxis teatrales se vuelven algunas de las recurrencias temáticas que rondan sus reflexiones acerca de las prácticas creadoras. La permeabilidad de las categorías usualmente reconocidas como fijas (especialmente las ideas de "afuera" y "adentro" de la escena), el reconocimiento de un material "autónomo" que tiene un saber propio, una "inteligencia sensible" y, especialmente, el despliegue -a través de los años- de lo que describen como "modo ensayo" son algunos de los decires ciertamente opacos pero con alta carga descriptiva que este grupo de mujeres imprime en sus praxis de creación. Lo que justifica la ausencia de un sistema fijo, recurrente y establecido a repetir obra tras obra es la posibilidad de entrar, justamente, en ese "modo ensayo". El mismo habilitaría la elaboración de obras a partir de "capas", propiciando el espacio "laboratorio" donde nacerá lo que ellas mencionan como "un hijo en común", "un Frankestein". Esto permite un abordaje de la escena que no requiere una dramaturgia previa, donde no hay jefe, no hay guía, ni "nadie que decida por los demás", en cambio se mantiene siempre una especie de voluntad de poner por delante una organización grupal autogestionada.

Estas matrices discursivas son las que conforman su "textualidad cifrada" (Blumenberg), única y específica, que responde a una concepción singular de la escena a modo de un microsistema teórico que no tiene voluntad ejemplificadora sino que son "cimiento" (como ellas refieren a las notas, a las imágenes y a las percepciones colectivas) de las propias praxis. Sus formas de referir a las prácticas de la escena incluyen diversas alusiones a conceptos clave que, en muchos casos, mutan y, en otros casos, se mantienen como redes del decir y del hacer dentro de la cotidianeidad de sus praxis.

Por otra parte, dentro de su recorrido, las instancias de formación en actuación -en la línea de la llamada dramaturgia de escena-y en dramaturgia sembraron las bases para la elaboración de ese sistema singular que -evidentemente- aporta a la construcción de un campo de saberes específico en la historia del teatro argentino, tal como se ha relevado en muchos otros casos estudiados dentro de este proyecto Filocyt.

A lo largo de estas páginas, una breve compilación de "imágenes directrices" (Blumenberg) ha buscado dar cuenta de ciertas unidades de sentido que plagan su pensamiento acerca de la creación teatral, que año tras año se reafirma colectivamente desde lo que ellas llaman el "desmenuzamiento de la mayoría". 


\section{Dibliografía}

» Bardet, M. (2012). Pensar con mover. Un encuentro entre danza y filosofía. Buenos Aires: Cactus.

»Bartís, R. (2003). Cancha con niebla. Buenos Aires: Atuel.

» Blumenberg, H. (2003). Paradigmas para una metaforología. Madrid: Editorial Trotta.

"González, L. (2020) Conversaciones Piel de Lava - Teatro Nacional Cervantes. En https://www.youtube.com/watch?v=WodoOQ-ooWM\&ab_ channel=CervantesOnline

"Paredes, L. (2018). “Un cuerpo solo. Apuntes sobre la creación grupal”. En La llave universal. URL: http://laveuniversal.com/2018/o6/o5/un-cuerpo-soloapuntes-sobre-la-creacion-grupal/

»Pellettieri, O. (1998). "El teatro de resistencia. El caso de Postales argentinas". Historia del teatro argentino en Buenos Aires. El teatro actual (1976-1998). Buenos Aires: Galerna.

"Pessolano, C. (2019). "Cuerpo de saberes, cuerpo de prácticas: notas sobre resistencia y reflexión en la escena argentina”. En Territorio Teatral http://www. territorioteatral.org.ar/numero/19/articulos/cuerpo-de-saberes-cuerpo-depracticas-notas-sobre-resistencia-y-reflexion-en-la-escena-argentina-carlapessolano

»Piel de Lava (2015). “La creación grupal”, Detrás de escena. Buenos Aires: Excursiones.

»Ure, A. (2003). Sacate la careta. Buenos Aires: Editorial Norma.

»Yaccar, M. D. (2017, 3 de agosto). “El universo en una playa” https://www.pagina12.com.ar/54093-el-universo-en-una-playa

» Yaccar, M. D. (2019, 14 de febrero). "Para nosotras, el grupo es una posición política” en https://www.pagina12.com.ar/174864-para-nosotras-el-grupo-esuna-posicion-politica 